http://dx.doi.org/10.32929/2446-8355.2019v28n2p152-165

\title{
REDES ALIMENTARES ALTERNATIVAS, AGROECOLOGIA E A CONSTRUÇÃO SOCIAL DE MERCADOS
}

\author{
Eugênio Martins de Sá Resende ${ }^{1 *}$, Alair Ferreira de Freitas ${ }^{2}$
}

\footnotetext{
${ }^{1}$ Mestrando no Programa de Pós-Graduação em Extensão Rural da Universidade Federal de Viçosa/UFV, Viçosa-MG. *E-mail do autor correspondente: geninhorede@gmail.com.

${ }^{2}$ Docente do Departamento de Extensão Rural da Universidade Federal de Viçosa/UFV, Viçosa-MG.
}

Recebido: 05/12/2018; Aceito: 13/06/2019

RESUMO: Os estudos dos sistemas agroalimentares, mesmo que recentes, têm apontado diversos impactos na forma como as pessoas no campo e nas cidades se alimentam, sobretudo a partir da Revolução Industrial e da Revolução Verde. Esses impactos são perceptíveis nos âmbitos ambiental, social, econômico e de saúde, fortalecendo cada vez mais os impérios agroalimentares a partir de regras e normas globais que excluem agricultores familiares camponeses e dificultam a comercialização de seus produtos em mercados formais e também locais e informais. No entanto, na Zona da Mata de Minas Gerais, apesar da predominância da monocultura do café, experiências locais baseadas na agroecologia e nas redes alimentares alternativas (RAA) vêm crescendo. A partir de metodologias da pesquisa participante como os intercâmbios agroecológicos, o objetivo desse trabalho foi descrever e analisar experiências agroecológicas e suas relações com os mercados, relacionando-as com as RAA. O estudo apontou que a agroecologia contribui para o desenvolvimento e ampliação dessas redes, a partir das relações sociais estabelecidas e na preocupação ambiental, ampliando os debates acerca dessas experiências locais.

Palavras-chave: Certificação. Circuitos curtos. Experiências locais. Mercados.

\section{ALTERNATIVE FOOD NETWORKS, AGROECOLOGY AND SOCIAL CONSTRUCTION OF MARKETS}

\begin{abstract}
Studies of agri-food systems, even if recent, have pointed to several impacts on the way people in the countryside and in cities feed, especially since the Industrial Revolution and the Green Revolution. These impacts are noticeable in the environmental, social, economic and health spheres, increasingly strengthening agrifood empires based on global rules and norms that exclude peasant family farmers and make it difficult to market their products in formal and local and informal markets. However, in the Zona da Mata of Minas Gerais, despite the predominance of coffee monoculture, local experiences based on agroecology and alternative food networks (AFN) have been increasing. Based on participatory research methodologies such as agroecological exchanges, the objective of this work was to describe and analyze agroecological experiences and their relationships with markets, relating them to the AFN. The study pointed out that agroecology contributes to the development and expansion of these networks, based on established social relations and environmental concern, broadening the debates about these local experiences.
\end{abstract}


Key words: Certification. Short circuits. Local experiences. Markets.

\section{INTRODUÇÃO}

A forma como as pessoas no campo e na cidade se alimentam tem se transformado radicalmente ao longo do tempo, sendo reflexo de profundas mudanças ambientais e socioeconômicas nos sistemas agroalimentares. Desde a Revolução Industrial com a abertura de novos mercados, a valorização do comércio em longas cadeias e a institucionalização da matriz tecnológica produtivista da Revolução Verde, que tecnificou e artificializou a agropecuária (SCHMITT; GRISA, 2013), tem-se registrado significativas alterações no padrão de alimentação global, desde a produção até o consumo.

Essas mudanças impactaram o meio ambiente a partir de práticas inadequadas na interação homem-natureza, como a redução da cobertura vegetal e da biodiversidade, inclusive de alimentos, o uso intensivo de agrotóxicos e adubos químicos sintéticos e a perda de qualidade dos solos e das águas (ALTIERI 2012; PEREZ-CASSARINO, 2013). Ademais, os âmbitos social e econômico também foram impactos, como a verticalização das cadeias produtivas centradas em grandes redes de supermercados, a exclusão de agricultores familiares camponeses e pequenos agricultores dos mercados, a concentração de terras e o aumento do êxodo rural e a desvalorização de conhecimentos locais e tradicionais (GOODMAN, 2017). De forma geral e englobando as questões ambientais e socioeconômicas, problemas coletivos de saúde advindos do uso indiscriminado de agrotóxicos e do aumento no consumo de produtos ultra processados, centrados em poucas culturas como a soja e o milho, são sintomas da depreciação desse novo padrão alimentar global.

No centro destas transformações temos um conjunto de alterações nas normas e marcos regulatórios relacionados às dinâmicas produtivas e comerciais do setor agroalimentar, como as mudanças nos aspectos de higiene e sanidade. Essas alterações estão centradas em padrões de qualidade globais como a durabilidade e a impessoalidade dos produtos, que ampliam cada vez mais a concentração e a integração de grandes empresas multinacionais em detrimento de camponeses e pequenos agricultores (SCHNEIDER; GAZOLLA, 2017). Essas mudanças passaram a requalificar os mercados e a produção agropecuária, ameaçando mercados de proximidade da agricultura familiar camponesa (RADOMSKI, 2013). Além disso, essas alterações impactaram as formas tradicionais de diferentes povos em produzir seus alimentos, centradas na relação estreita entre homem-natureza em que a biodiversidade e os ciclos naturais são centrais na manutenção dos processos produtivos e culturais que garantem a soberania e a segurança alimentar e nutricional desses povos.

A justificativa de todas essas mudanças era a necessidade do aumento na produção de alimentos para acabar com a fome no mundo, o que de fato não aconteceu (MALUF, 2007). Niederle e Marques (2016) apontam que a questão não é mais a quantidade de alimentos, mas sim a qualidade deles, assim como os caminhos desde a produção até o consumo. Nesse bojo, diferentes escândalos relacionados à qualidade dos alimentos vêm acontecendo no mundo, gerando desconfianças por parte da população em relação à produção industrial moderna. 
Apesar desses impactos da globalização, sobretudo sobre os públicos mais marginalizados do campo e das cidades, diferentes experiências marcadas por fluxos culturais locais surgem em todo o mundo. Nesse sentido, emergem movimentos que valorizam os alimentos naturais, sem agrotóxicos e de qualidade, expressos na aproximação entre produção e consumo, que baseados nas conexões entre agricultura-coletividade-alimentação-saúdebiodiversidade-energia-democracia, desafiam o modelo economicista e produtivista (MARSDEN et al., 2017). Chamadas de Redes Alimentares Alternativas (RAA) ou alternative food network (AFN) em inglês, Renting et al. (2017) as definem como formas emergentes em que diferentes atores incorporam alternativas ao modo industrial padronizado e dominante de produção e abastecimento alimentar. Nestas RAA a aproximação entre produtores e consumidores é essencial, assim como as relações sociais entre esses e outros atores estabelecidas a partir de redes sociais. No quadro abaixo são demarcadas as diferenças entre as RAA e as redes alimentares convencionais.

Quadro 1. Comparação entre as características das redes alimentares convencionais e alternativas. Comparison between the characteristics of conventional and alternative food networks.

\begin{tabular}{|c|c|}
\hline CONVENCIONAL & ALTERNATIVA \\
\hline Moderno & Pós-moderno \\
\hline Industrializado/processado & Natural/fresco/agroindústria familiar ou \\
comunitária
\end{tabular}

Fonte: adaptado de Maye e Kirwan (2010). Source: adapted from Maye e Kirwan (2010).

Além disso, diversos autores reforçam que a agroecologia e a produção de base familiar nos diferentes territórios assim como a construção e o acesso aos mercados, são questões importantes na construção de alternativas ao modelo hegemônico e excludente (DE SCHUTTER, 2012; IAASTD, 2009; MIER Y TERÁN GIMÉNEZ CACHO et al., 2018; PETERSEN et al., 2017).

No Brasil, o movimento agroecológico existe desde a década de 70, mas foi a partir das décadas de 80 e 90 com a redemocratização do país, que ele ganha mais força (COSTA et al., 2015). No início do século XXI instituições focadas na agroecologia são criadas, dentre elas a 
Articulação Nacional de Agroecologia (ANA), que engloba tanto as organizações de agricultores e agricultoras e de povos e comunidades tradicionais quanto da sociedade civil, e, no campo da ciência, criou-se a Associação Brasileira de Agroecologia (ABA) que reúne pesquisadores e instituições de ensino e pesquisa. De forma a expandir a construção da agroecologia a partir dos diferentes contextos territoriais, diversas redes e articulações surgiram em diferentes estados e regiões do Brasil, trazendo novas questões para o debate.

Diante disso, há uma demanda crescente em ampliar as análises das experiências alternativas ao sistema agroalimentar convencional, dando visibilidade e compreensão acadêmica às experiências de caráter local. Explicitar a prática e sua interface com as abordagens teóricas pode contribuir para avançar no diálogo científico sobre a reconfiguração de sistemas agroalimentares e sobre novos modelos organizativos de abastecimento alimentar voltados para a saúde humana e a sustentabilidade ambiental.

A partir dessas conexões, definiu-se a Zona da Mata de Minas Gerais como território desse trabalho, tanto pela sua trajetória de construção da agroecologia há cerca de 30 anos quanto pela presença de organizações produtivas e suas experiências de encurtamento das redes alimentares. Este trabalho teve como objetivo principal descrever e analisar duas experiências agroecológicas desenvolvidas nos municípios de Araponga-MG e Pedra Dourada-MG, desvelando os mecanismos de acesso à diferentes mercados e seu papel no desenvolvimento de redes alimentares alternativas.

\section{MATERIAL E MÉTODOS}

A pesquisa de campo baseou-se na pesquisa participante, em que parte-se da relação estreita entre pesquisadores e sujeitos e de metodologias participativas e dialógicas. O trabalho de campo foi realizado entre os meses de agosto e novembro de 2017 a partir de excursões científicas com outros pesquisadores da Universidade Federal de Viçosa (UFV). Essas excursões foram baseadas nos intercâmbios agroecológicos, que já se expandiram para a Zona da Mata de MG e constituem um conjunto de dispositivos metodológicos que promovem o processo de aprendizagem a partir da socialização e da construção do conhecimento entre diversos sujeitos, sejam eles agricultores/as, técnicos ou estudantes, tendo por base o diálogo e a horizontalidade entre conhecimento popular e científico (ZANELLI et al., 2015). Esse conjunto compõe as metodologias da pesquisa participante, reforçando a importância do princípio da indissociabilidade entre ensino, pesquisa e extensão que consta no Artigo 207 da Constituição Brasileira (BRASIL, 1988). Da mesma forma, não há divisão da teoria e da prática e, como Freire (1982) afirma, não basta ter o domínio do conhecimento, é necessário estabelecer ambientes que propiciem o diálogo de forma que o conhecimento seja construído e inteligível para os atores.

As propriedades foram escolhidas a partir da proximidade, acessibilidade e disponibilidade das famílias em receberem pesquisadores e atividades acadêmicas, além da longa experiência dessas famílias na construção da agroecologia. Destaca-se que essas famílias participam da rede de promoção da agroecologia iniciada ao final da década de 80 na Zona da Mata de MG, ou seja, de quase 40 anos. Inicialmente essa rede foi estimulada pelo Centro de Tecnologias Alternativas da Zona da Mata (CTA-ZM), organização não 
governamental fundada em 1987 que atua na região com agroecologia e agricultura familiar, mas hoje apresenta uma configuração multicêntrica reunindo um conjunto bastante amplo de ações e instituições para além do CTA-ZM (SCHMITT, 2016).

As informações e elementos de análise foram levantados a partir de técnicas do Diagnóstico Rápido Participativo (DRP) como a caminhada transversal. Nessa técnica, os atores participantes percorrem as propriedades, em que os integrantes das famílias apresentam seus diferentes agroecossistemas, e que, a interação com os pesquisadores, permite questionamentos e aprofundamentos sobre esses sistemas. Durante as caminhadas e após elas, entrevistas não diretivas eram realizadas, pautadas pela liberdade do interlocutor na abordagem do tema de interesse da pesquisa, possibilitando reflexões e interpretações dos integrantes das famílias entrevistadas (FIALHO, 2015). Além disso, observou-se durante a caminhada transversal nas propriedades, os discursos dos sujeitos, incluindo os pesquisadores, assim como as paisagens e outros elementos relacionados com o objeto da pesquisa, sendo todas as informações registradas em caderno de campo.

Os intercâmbios e as entrevistas foram realizados com os integrantes das famílias que participaram das atividades, sendo que no município de Araponga-MG participaram o homem e o filho e no município de Pedra Dourada-MG o homem, a mulher, a filha e o filho. De forma complementar, realizou-se análise documental com a finalidade de analisar documentos como fontes paralelas e simultâneas de informação que possam complementar os dados levantados in loco e contextualizar as informações.

\section{RESULTADOS E DISCUSSÃO}

Os municípios de Araponga e Pedra Dourada estão localizados na Zona da Mata, sudeste de Minas Gerais, estado com maior produção de café arábica do país (IBGE, 2017) ${ }^{1}$. Ambos os municípios estão em região declivosa e com altitudes acima de $600 \mathrm{~m}$ que favorecem a produção do café arábica, sendo que de acordo com o IBGE (2017) ArapongaMG é o $14^{\circ}$ município do estado com maior número de estabelecimentos produtores de café (1374), sendo que o primeiro é Manhuaçu-MG, com 2.743. De acordo com as pesquisas de De Almeida e Zylbersztajn (2017), a produção cafeeira na Zona da Mata tem as seguintes características: trabalho intensivo de meeiros e da própria família, a qualidade do produto ainda é pouco explorada, forte presença de intermediários como canais de comercialização mas com crescente participação na venda direta, para exportação e participação em concursos de qualidade e poucas propriedades com certificações de sustentabilidade como a produção orgânica e agroecológica ou do mercado justo, mas em franco crescimento.

Diferentemente dos agroecossistemas de ambas as famílias, o café na região é produzido na forma de monocultura, a pleno sol, com o uso intensivo de adubos químicos sintéticos e agrotóxicos, além da contratação temporária de mão de obra principalmente na colheita. A partir da trajetória das famílias com a agroecologia, ambas as propriedades são diversificadas e possuem árvores em seus sistemas produtivos, o que chamamos de Sistemas

${ }^{1}$ https://censos.ibge.gov.br/agro/2017/templates/censo_agro/resultadosagro/agricultura.html?localidade=31\&tem $\mathrm{a}=76252$ 
Agroflorestais (SAFs). Ainda, não utilizam adubos químicos sintéticos e agrotóxicos e possuem nas redes sociais estabelecidas na comunidade e na família a mão de obra necessária à produção ${ }^{2}$. Possuem certa autonomia tanto no acesso a insumos produtivos como adubos orgânicos, sementes crioulas e ração animal caseira, como também na produção para o autoconsumo, não utilizam intermediários na comercialização dos produtos e possuem uma grande biodiversidade. Chama atenção a diversificação da renda das famílias, que além dos diferentes mercados acessados, possuem outras atividades como o Turismo Rural ou ecoturismo.

Uma característica comum entre os municípios é a proximidade com unidades de conservação como o Parque Estadual da Serra do Brigadeiro (PESB) em Araponga-MG e o Parque Nacional do Caparaó (PARNA Caparaó) em Pedra Dourada-MG. Além de ser um incentivo à preservação ambiental, permite também a pluriatividade e a diversificação da renda em atividades como hospedagem, fornecimento de refeições e a comercialização direta da produção familiar para turistas e através de hotéis e pousadas.

Apesar da diversificação, o café continua sendo o produto principal da região, e a busca por mercados diferenciados para o café agroecológico da região foi iniciada nos primeiros anos do século XXI. Entre 2001 e 2002, o CTA-ZM, juntamente com os parceiros locais e regionais $^{3}$, desenvolveu o Plano Estratégico do Café Agroecológico (PEC). O objetivo desse plano era identificar os problemas e as possibilidades de melhorias nos sistemas de produção, no beneficiamento e na comercialização do café agroecológico, definindo estratégias conjuntas de atuação.

Uma das estratégias na época foi a certificação orgânica participativa do café, que, juntamente com outros grupos de agricultores familiares das regiões Sul e Leste de Minas Gerais, buscavam junto a já extinta Associação de Certificação de Produtos Orgânicos Sapucaí localizada no Sul de MG, a certificação orgânica do café, que abriria o mercado de exportação. No entanto, a certificação não se efetivou naquela época para os agricultores da Zona da Mata, mas as discussões contribuíram na construção da regulamentação da produção orgânica no Brasil que teria, ao final de 2003, a sanção da Lei Federal 10.831 que dispõe sobre a agricultura orgânica e dá outras providências.

O fato de não conseguirem a certificação orgânica fez com que o café agroecológico naquela época fosse comercializado como produto convencional, o que decepcionou muitos agricultores familiares que acabaram se afastando do grupo. Ambas as famílias pesquisadas participaram desse processo e não desistiram da produção agroecológica do café e dos demais produtos. No entanto, em Pedra Dourada, a família ainda buscou depois dessa experiência malsucedida a certificação por auditoria por meio da Associação de Agricultores Biológicos do Estado do Rio de Janeiro (ABIO). Devido à distância de outros agricultores agroecológicos

\footnotetext{
${ }^{2}$ Dados preliminares do Censo Agropecuário 2017 apontam que das 4256 pessoas ocupadas em estabelecimento agropecuário em Araponga-MG, 2986 possuem laço de parentesco com o produtor, ou seja, mais de $70 \%$ das pessoas.

${ }^{3}$ Dentre os parceiros destacamos os Sindicatos dos Trabalhadores Rurais (STR), a UFV e as associações municipais e regionais de agricultores, já que naquela época o movimento cooperativista da agricultura familiar ainda era incipiente na região.
} 
interessados na certificação e as dificuldades em relação aos custos e aos controles necessários, a mesma não se efetivou, apesar da família possuir práticas agroecológicas muito avançadas. Wilkinson (2008) aponta que as mudanças nos aspectos de higiene, sanidade e controle para se adaptar às regras impessoais dos mercados, inclusive no mercado de produtos orgânicos, podem trazer dificuldades aos agricultores familiares e camponeses.

Já em Araponga, um grupo reduzido de agricultores familiares, cerca de 10 famílias, que possuíam relações familiares próximas, continuou a busca pela certificação orgânica. A relação com o Sul de MG continuou através, inicialmente, da Cooperativa Agropecuária de Produtores Orgânicos de Nova Resende (COOPERVITAE) e depois a Cooperativa de Agricultores Familiares de Poço Fundo (COOPFAM), em que são cooperados até então. A partir dessas cooperativas que já tinham uma organização para a exportação de café, conseguiram a certificação orgânica e do mercado justo ${ }^{4}$ para o café. Esse pioneirismo incentivou que outras famílias também participassem do grupo em Araponga, inclusive de outros municípios próximos. Além disso, em 2015, outro grupo foi formado no município de Divino-MG, que também faz parte da rede de promoção da agroecologia da Zona da Mata e que já engloba também agricultores de municípios vizinhos.

No entanto, o desafio da comercialização posto pelos agricultores e suas organizações permanece e outras ações relacionadas a construção dos mercados para os produtos agroecológicos aconteceram, como a diversificação da produção para além do café, o acesso aos circuitos curtos de comercialização como as feiras e compras institucionais como o Programa de Aquisição de Alimentos (PAA) e o Programa Nacional de Alimentação Escolar (PNAE), a criação dos mercadinhos da agricultura familiar ${ }^{5}$, a organização e formalização de Associações e Cooperativas de Agricultores entre outras. Muitas dessas conquistas estão diretamente relacionadas com a atuação junto ao movimento sindical, com os movimentos de base da igreja católica e com organizações da sociedade civil como o CTA-ZM e as cooperativas e associações de agricultores. Destaca-se a proximidade com o corpo docente e discente da UFV, que realiza atividades de ensino, pesquisa e extensão voltadas para a agricultura familiar agroecológica, nesses e em outros municípios da região, que também cooperam para o avanço das ações.

Percebe-se que se forma uma rede com diversos atores, reforçando a importância das relações estabelecidas. No âmbito das pesquisas sobre o café agroecológico, importante destacar a parceria com a Empresa de Pesquisa Agropecuária de Minas Gerais (EPAMIG) que realizou experimentos com variedades mais adaptadas à produção orgânica e de adubos orgânicos mais eficientes, sempre de forma participativa com os agricultores. Da mesma

\footnotetext{
${ }^{4}$ A missão do mercado justo ou Fair Trade Internacional em inglês é conectar produtores e consumidores desfavorecidos, promover condições comerciais mais justas e capacitar os produtores para combater a pobreza, fortalecer sua posição e assumir mais controle sobre suas vidas. (Fonte: https://www.fairtrade.net/aboutfairtrade)

5 São pontos fixos de comercialização de produtos da agricultura familiar, normalmente vinculados aos Sindicatos dos Trabalhadores Rurais (STR) e outras organizações parceiras, que também funcionam como um entreposto entre os produtos da zona rural e a cidade. Além disso, possuem também produtos convencionais de consumo dos agricultores como lâminas para roçadeira, sapatos, entre outros, fazendo com que os recursos financeiros circulem dentro das organizações da agricultura familiar.
} 
forma o CTA-ZM e a UFV incentivaram a partir de 1994 a implantação do café sombreado a partir dos Sistemas Agroflorestais e em 2003 realizaram a sistematização participativa das experiências com SAFs dos agricultores acompanhados pelo CTA-ZM ${ }^{6}$. Essa sistematização foi base para que os agricultores, a partir dos aprendizados construídos participativamente com os atores envolvidos, desenvolvessem e adaptassem às suas necessidades o manejo das árvores, a escolha das espécies, a adubação e ciclagem de nutrientes entre outras, que hoje são realizadas nos agroecossistemas.

A partir dessa diversidade de parcerias estabelecidas e ações realizadas, foi possível a construção social de outros mercados. Além desse mercado baseado na certificação orgânica e no mercado justo, a confiança, a cooperação e a valorização de produtos com qualidade diferenciada como os agroecológicos também são quesitos importantes. Como aponta Radomsky (2013), para se adequar aos padrões das transações internacionais e também às normas, demandas e especificidades dos diferentes mercados, as famílias agricultoras devem ter seus agroecossistemas organizados e identificados. Como observado nas propriedades durante a caminhada transversal, as famílias dividem as lavouras de café diversificadas conforme as exigências dos mercados acessados. Em Araponga destacamos três talhões diferenciados, que são: 1- café para o mercado justo orgânico comercializado para a América do Norte, que não utilizam a cama de frango como adubo orgânico pois não é permitido; 2café para o mercado justo orgânico comercializado para a Europa, que permite o uso da cama de frango desde que deixada em repouso durante cerca de 2 meses antes da adubação; e uma terceira forma, que também é o manejo utilizado em toda a propriedade em Pedra Dourada, focado no mercado da Agricultura Natural ${ }^{7}$. Nesse caso, apesar de não haver nenhuma certificação orgânica ou outra específica para a Agricultura Natural, não se utiliza nenhum insumo externo ao talhão, apenas o que está presente naquele agroecossistema como as folhas, frutos e galhos das árvores, as plantas espontâneas e a palha do café que é colhido no próprio talhão, demonstrando a importância do equilíbrio e da ciclagem de nutrientes nos agroecossistemas, como defende a agroecologia. Esse café da agricultura natural é comercializado exclusivamente junto a Shumei em São Paulo ${ }^{8}$ desde 2013.

A construção desse mercado para o café natural precisa de um melhor detalhamento. $\mathrm{O}$ modelo econômico dominante desde o século XVIII baseia-se na economia de mercado,

\footnotetext{
${ }^{6}$ Para mais informações consultar o documento "Sistematização das experiências com sistemas agroflorestais do CTA-ZM-relatório final" através lo link: http://www.mma.gov.br/estruturas/pda/_arquivos/prj_mc_035_pub_rel_001_ae.pdf

${ }^{7}$ A Agricultura Natural desenvolvida no Japão é uma das correntes da chamada Agricultura Alternativa, entre outras como a Agricultura Biodinâmica na Alemanha e a Agricultura Orgânica desenvolvida nos Estados Unidos e na Inglaterra.

${ }^{8}$ A Shinji Shumeikai, conhecida como Shumei, é uma organização espiritual dedicada a elevar a qualidade de vida das pessoas, comprometida com a criação de um estado ideal de saúde, felicidade e harmonia, pondo em prática a sabedoria e compreensão do seu líder espiritual, Mokichi Okada. Ele ensinou que um mundo livre de doenças, pobreza e discórdia é possível através do exercício espiritual do Jyorei, da contemplação da arte e da beleza e da prática da Agricultura Natural. Como método de agricultura, ela precisa entender as relações físicas sutis e os vínculos espirituais que existem entre todos os elementos envolvidos no cultivo do alimento: a terra, o sol, a chuva, o vento, o agricultor, as pessoas que consomem o alimento e a sociedade na qual eles vivem. E seu propósito é nutrir a saúde e o bem-estar de todos estes elementos. (Fonte: http://shumei.org.br).
} 
autorregulado a partir da oferta e da demanda de produtos, em que a motivação da subsistência do ser humano baseia-se apenas no lucro e no máximo de ganhos monetários, sem influências da sociedade. No entanto, a sociologia econômica, que une a economia e a sociologia, trouxe à tona outros elementos de análise para a vida econômica. Um deles é o pressuposto de que as relações sociais edificam a economia e tanto a sociedade influencia como é influenciada pelos fenômenos econômicos, ou seja, a economia é um fenômeno social por natureza (SWEDBERG, 2004). Nesse sentido, as estratégias de comercialização, a construção social dos mercados e a conformação de redes sociais são métodos e conceitos da sociologia aplicadas aos fenômenos econômicos.

De acordo com Antunes (2012), a rede social é um instrumento analítico que pode ser utilizado para a análise de diversas situações sociais, como as estratégias de comercialização e construção social dos mercados. Essas redes podem ser entendidas como um campo formado pelas interações entre as pessoas e suas instituições que podem estabelecer relações de amizade, parentesco entre outras, estabelecendo conexões econômicas. As transações realizadas nos mercados também são interações sociais entre atores, sejam eles produtores, comerciantes, atravessadores, consumidores, transportadores entre outros possíveis, em que as relações existentes são mais importantes do que os próprios atores.

A partir das redes sociais, Mark Granovetter (1973) classificou as relações dos indivíduos internamente nas redes como laços fortes, como as relações de parentesco, de amizade, entre outras e de laços fracos as relações estabelecidas para além dos laços fortes internos a uma rede, em que, indivíduos que também participam de outras redes, estabelecem relações para além da rede inicial ou primária de parentesco ou amizade. Foi dessa forma que a comercialização do café natural se iniciou.

A partir de uma apresentação de experiências agroecológicas de SAFs na Zona da Mata de MG por um estudante da UFV na Suécia em 2012, representantes da Shumei se interessaram em conhecer a produção agroecológica de café da região. A partir disso, um representante da organização no Brasil veio conhecer pessoalmente as propriedades e seus sistemas produtivos, sobretudo as famílias assessoradas pelo CTA-ZM. A partir dessa visita, dentre as propriedades que conheceram, algumas famílias chamaram à atenção e então já acordaram uma primeira entrega do café de forma a avaliarem a qualidade. $\mathrm{O}$ café foi aprovado e desde 2013 compram anualmente o café natural de oito famílias dos municípios de Araponga e Pedra Dourada, já apontando que possuem uma demanda maior do produto.

Com o estabelecimento desse mercado, anualmente são feitas visitas nas propriedades pelos representantes da organização. Desde a primeira visita, os valores éticos, sociais e culturais, além de princípios como autonomia, confiança e respeito às culturas (DAROLT, 2013) ficam claros nas relações estabelecidas entre os atores. Um dos agricultores entrevistados relata que durante uma visita de representantes da Shumei de outros países, além do Brasil, em sua propriedade, um dos integrantes o abraçou e relatou que o sistema produtivo desenvolvido na propriedade era o mesmo do povo deles. Isso ressalta a importância da cultura e das identidades dos povos de forma que novas práticas econômicas e ecológicas possam surgir. 
A confiança estabelecida entre os atores também deve ser destacada. As famílias relatam que não há nenhum documento que formalize o compromisso de compra e venda, mas que desde o primeiro ano nunca tiveram problemas ou dificuldades com os pagamentos e com o envio do café. Pela excelente qualidade do produto e pela divulgação desse mercado, as famílias já receberam propostas de compra inclusive por valores de venda maiores do que os negociados ${ }^{9}$ com a Shumei, mas nunca aceitaram já que esse tipo de comprador-atravessador é pontual e não há garantias e confiança estabelecida.

Essa relação estreita estabelecida entre consumidor-produtor favorece também outras negociações. No ano de 2017, antes da colheita do café, a família de Pedra Dourada negociou um adiantamento financeiro, permitindo que adquirissem um limpador de café para evitar as perdas de qualidade e quantidade ${ }^{10}$ do café ao beneficiá-lo em máquinas coletivas que beneficiam cafés convencionais no município. Depois de beneficiado (descascado e selecionado) é que o café é enviado, sendo que diferentes formas de envio são utilizadas.

Apesar de não haver contrato formal, a Shumei exige a emissão das notas fiscais e do pagamento de todos os impostos necessários, tudo pago pela organização, inclusive os custos com transporte se houverem. Dentre as formas utilizadas na entrega do produto temos o envio pelos correios, a entrega direta nas propriedades produtoras, o envio por ônibus de linha e o fretamento de empresa terceirizada para o transporte até o destino. Apesar do comprador ser o mesmo, o grupo de Araponga tem estratégia diferente. Já que é uma quantidade maior de sacas, realiza toda a transação comercial pela COOPFAM, cooperativa que também exporta o café orgânico no mercado justo e que já possui toda a estrutura necessária. A forma de entrega é definida e negociada entre a Shumei e cada uma das famílias, levando em consideração as facilidades por parte dos agricultores, as garantias de manutenção da qualidade do produto e os valores gastos durante o transporte. De toda forma, os valores agregados ao produto são bem superiores que no mercado convencional.

Além das diferenças entre esse mercado baseado na confiança e o mercado convencional de uma commodity como o café, já apontadas acima, os valores financeiros também são diferenciados. Para exemplificar, na safra de café colhida em 2017, a família de Pedra Dourada vendeu o café beneficiado (limpo, selecionado e crú) na propriedade, selecionado nas peneiras 15 e 16 e com qualidade da bebida de dura para melhor no valor líquido de $\mathrm{R} \$ 2.100,00$ a saca de 60kg. Comparando-se com os valores do mercado convencional, a partir da cotação do café no Centro do Comércio de Café do Estado de MG, no mesmo período da transação com a Shumei (agosto e novembro de 2017), o maior valor registrado de venda do café (B/C, tipo 6, bebida dura, peneira 15) foi de $\mathrm{R} \$ 470,00^{11}$, ou seja, valor mais de 4 vezes inferior ao valor vendido, sem levar em conta os custos que a família ainda teria que arcar.

\footnotetext{
${ }^{9}$ Importante destacar que os valores de venda são negociados anualmente entre as famílias e o representante da organização no Brasil.

${ }^{10}$ Ao utilizar uma máquina que também limpa café convencional, parte inicial do café agroecológico beneficiado é separado, no intuito de evitar contaminação com restos de grãos que permanecem na máquina.

${ }^{11}$ Fonte: http://cccmg.com.br/consultar-periodo-cotacao/
} 


\section{CONCLUSÃO}

As análises da conformação de RAA não devem ser simplificadas e baseadas apenas na racionalidade econômica, mas também nas relações sociais estabelecidas e na preocupação ambiental, assim como baseia-se a agroecologia. Observando as características da agroecologia, assim como das RAA, as experiências analisadas corroboram com grande parte delas, como a cooperação social, a redução da distância entre produção e consumo, a escala e o tamanho reduzido dos estabelecimentos, a dinamização de mercados e sua autonomia no acesso, a revalorização de produtos de qualidade como os produtos agroecológicos, e compromissos com as dimensões sociais, econômicas e ambientais da produção ao consumo. Essas experiências, em sua natureza e dinâmica operacional, apontam a agroecologia como base para o desenvolvimento dessas novas redes alimentares. No entanto, elas não estão totalmente desconectadas das redes convencionais, como é o caso do café no mercado justo e orgânico em que seus preços de mercado são baseados na bolsa de valores. Há, portanto, valores, princípios e comportamentos associados à agroecologia, mas as estratégias de subsistência dessas famílias compõem um modelo híbrido entre o "alternativo" e o "convencional".

É evidente que o componente econômico é um dos pilares mais importantes à comercialização de produtos da agricultura familiar agroecológica. Mas, como aqui se operou, esses processos devem ser analisados, a partir da ótica da sociologia econômica, partindo do princípio de que a vida econômica está intimamente atrelada e é condicionada pelas relações sociais e que as atividades comerciais não podem ser apartadas de seu contexto social. Nesse sentido, mercados baseados na confiança, na cooperação, na estreita relação produtorconsumidor e na valorização de produtos com qualidade diferenciada também são importantes para as famílias, mesmo que nestes a troca monetária não seja regente principal das transações.

As experiências apontam a necessidade de um debate ampliado correlacionando as vantagens e desvantagens para os agricultores familiares em relação às certificações, sobretudo a orgânica. As mudanças que ocorrem constantemente para favorecer as grandes cadeias de abastecimento alimentar trazem dificuldades aos agricultores familiares e camponeses tanto na produção como na comercialização de seus produtos. Aprofundar as análises sobre a construção social dos mercados e a resiliência das experiências de redes alimentares alternativas é uma agenda de pesquisa em grande acessão, mas que ainda carece de intensos esforços analíticos.

\section{AGRADECIMENTOS}

Agradeço ao corpo docente e discente do Programa de Pós-Graduação em Extensão Rural da UFV, à CAPES/CNPQ, aos agricultores e agricultoras e ao CTA-ZM.

O presente trabalho foi realizado com apoio da Coordenação de Aperfeiçoamento de Pessoal de Nível Superior - Brasil (CAPES) - Código de Financiamento 001. 


\section{REFERÊNCIAS BIBLIOGRÁFICAS}

ALTIERI, M. A. Agroecologia: bases científicas para uma agricultura sustentável. São Paulo; Rio do Janeiro: Expressão Popular; AS-PTA, 2012. 400 p.

ALMEIDA, L. F.; ZYLBERSZTAJN, D. Key success factors in the brazilian coffee agrichain: present and future challenges. International Journal on Food System Dynamics, Bonn, v. 8, n. 1, p.45-56, 2017. Disponível em: http://centmapress.ilb.unibonn.de/ojs/index.php/fsd/article/view/814. Acesso em: 5 dez. 2018.

ANTUNES, C. A história da análise de redes e a análise de redes em história. História, Revista da FLUP, Porto, v. 2, n. 4, p.11-22, 2012.

BRASIL. Constituição [1988]. Constituição da República Federativa do Brasil de 1988. Brasília, DF, $1988 . \quad$ Disponível em: http://www.planalto.gov.br/ccivil_03/constituicao/constituicao.htm. Acesso em: 26 mar. 2018.

COSTA, M. B. B.; SOUZA, M.; JÚNIOR, V. M.; COMIN, J. J.; LOVATO, P. E. Agroecologia no Brasil: 1970 a 2015. Agroecologia, [s. 1.], v. 10, n. 2, p.63-75, 2015.

DAROLT, M. R. Circuitos curtos de comercialização de alimentos ecológicos: reconectando produtores e consumidores. In: NIEDERLE, P. A.; ALMEIDA, L.; VEZANNI, F. M. (org.). Agroecologia: práticas, mercados e políticas para uma nova agricultura. Curitiba: Kairós, 2013. p. 139-170.

FIALHO, M. A. V. Observações e interpretações sobre populações rurais em regiões de pobreza: etnografia e experiências de campo. In: RADOMSKY, G. F. W.; CONTERATO, M. A.; SERGIO SCHNEIDER (org.). Pesquisa em desenvolvimento rural: técnicas, bases de dados e estatística aplicadas aos estudos rurais. Porto Alegre: Editora da UFRGS, 2015. p. 37-54.

FREIRE, P. Criando métodos de pesquisa alternativa: aprendendo a fazê-la melhor através da ação. In: BRANDÃO, C. R. (org.) Pesquisa participante. 2. ed. São Paulo: Brasiliense, 1982. p. 34-41.

GOODMAN, D. Espaço e lugar nas redes alimentares alternativas: conectando produção e consumo. In: GAZOLLA, M.; SCHNEIDER, S. (org.). Cadeias curtas e redes agroalimentares alternativas: negócios e mercados da agricultura familiar. Trad. Regina Beatriz A. Vargas. Porto Alegre: Editora da UFRGS, 2017. p.59-82. (Estudos Rurais).

GOODMAN, D.; DUPUIS, E. M.; GOODMAN, M. K. Alternative food networks: knowledge, practice and politics. New York: Routledge, 2012. 308 p.

GRAnOVETTER, M. S. The strength of weak ties. The American Journal os Sociology, Chicago, v. 78, n. 6, p.1360-1380, 1973.

INTERNATIONAL ASSESSMENT OF AGRICULTURAL KNOWLEDGE, SCIENCE, AND TECHNOLOGY FOR DEVELOPMENT (PROJECT); MCINTYRE, Beverly D. (org.). Global report. Washington, DC: Island Press, 2009. 590 p. (Agriculture at a crossroads).

MALUF, R. S. J. Segurança alimentar e nutricional. Petrópolis: Vozes, 2007. 174 p. 
MAYE, D.; KIRWAN, J. Alternative food networks. [S. 1.]: Editorial Arrangement of Sociopedia.isa, $2010 . \quad$ Disponível em: http://www.sagepub.net/isa/admin/viewPDF.aspx?\&art=Alternative\%20Food\%20Networks.p df. Acesso em: 29 mar. 2018.

MIER Y TERÁN GIMÉNEZ CACHO, M.; GIRALDO, O. F.; ALDASORO, M.; MORALES, H.; FERGUSON, B. G.; ROSSET, P.; KHADSE, A.; CAMPOS, C. Bringing agroecology to scale: key drivers and emblematic cases. Agroecology and Sustainable Food Systems, New York, v. 42, n. 6, p. 637-665, 2018.

NIEDERLE, P. A.; MARQUES, F. C. Produção ecológica de alimentos e mudanças institucionais: implicações para a construção de novos mercados. In: MARQUES, F. C.; CONTERATO, M. A.; SCHNEIDER, S. (org.). Construção de mercados e agricultura familiar-desafios para o desenvolvimento rural. Porto Alegre: Editora da UFRGS, 2016. cap. 11 , p. $275-307$.

PEREZ-CASSARINO, J. Agroecologia, mercados e sistemas agroalimentares: uma leitura a partir da soberania e segurança alimentar e nutricional. In: Agroecologia: princípios e reflexões conceituais. Brasília, DF: Embrapa, 2013. cap. 05, p. 181-230. (Transição Agroecológica, 1).

PETERSEN, P.; SILVEIRA, L. M.; FERnANDES, G. B.; ALMEIDA, S. G. Método de análise econômico-ecológica de agroecossistemas. Rio de Janeiro: AS-PTA, 2017. 246 p.

RADOMSKY, G. F. W. Certificações, sistemas participativos de garantia e agricultura ecológica: aspectos da relação entre agricultores e consumidores. In: NIEDERLE, P. A.; ALMEIDA, L.; VEZANNI, F. M. (org.). Agroecologia: práticas, mercados e políticas para uma nova agricultura. Curitiba: Kairós, 2013. p. 297-325.

RENTING, H.; MARSDEN, T.; BANKS, J. Compreendendo as redes alimentares alternativas: o papel de cadeias curtas de abastecimento de alimentos no desenvolvimento rural. In: GAZOLLA, M.; SCHNEIDER, S. (org.). Cadeias curtas e redes agroalimentares alternativas: negócios e mercados da agricultura familiar. Trad. Regina Beatriz A. Vargas. Porto Alegre: Editora da UFRGS, 2017. p. 27-51. (Estudos Rurais).

SCHMITT, C. J. Agroecologia, políticas públicas e transições sociotécnicas: ampliação de escala de redes territoriais voltadas à promoção de uma agricultura de base ecológica. Rio de Janeiro: CPDA/UFRRJ, 2016. 240 p.

SCHMITT, C. J.; GRISA, C. Agroecologia, mercados e políticas públicas: uma análise a partir dos instrumentos de ação governamental. In: NIEDERLE, P. A.; ALMEIDA, L.; VEZZANI, F. M. (org.). Agroecologia: práticas, mercados e políticas para uma nova agricultura. Curitiba: Kairós, 2013. p. 215-266.

SCHNEIDER, S.; GAZOLLA, M. Cadeias curtas e redes agroalimentares alternativas. In: GAZOLLA, M.; SCHNEIDER, S. (org.). Cadeias curtas e redes agroalimentares alternativas: negócios e mercados da agricultura familiar. Porto Alegre: UFRGS, 2017. p. 09-24. (Estudos Rurais). 
SCHUTTER, O. Agroecologia e o direito humano à alimentação adequada. Brasília, DF: MDS, 2012.

Disponível

em: http://www.mds.gov.br/webarquivos/publicacao/seguranca_alimentar/caderno1_sisan2012.pd f. Acesso em: 5 dez. 2018.

WEDBERG, R. Sociologia econômica: hoje e amanhã. Tempo Social, São Paulo, v. 16, n. 2, p.7-34, 2004. Disponível em: http://www.scielo.br/scielo.php?script=sci_arttext\&pid=S010320702004000200001\&lng=pt\&nrm=iso\&tlng=pt. Acesso em: 24 nov. 2018.

WILKINSON, J. Mercados, redes e valores: o novo mundo da agricultura familiar. Porto Alegre: UFRGS: Programa de Pós-graduação em Desenvolvimento Rural, 2008. 213 p. (Estudos Rurais).

ZANELLI, F. V.; LOPES, A. S.; CARDOSO, I. M.; FERNANDES, R. B. A.; SILVA, B. M. Intercâmbios agroecológicos: aprendizado coletivo. Informe Agropecuário: Agricultura Orgânica e Agroecologia, Belo Horizonte, v. 36, n. 287, p.124, 2015. 